\title{
Effects of Plant Mediated Therapy Activity on College Students' Academic Burnout and Stress
}

\author{
Min Hui Lee', Yong Hyun Kim ${ }^{1,2}$, Eun Jung Park ${ }^{3}$, and Moo Ryong Huh ${ }^{1,2}$ * \\ ${ }^{1}$ Department of Horticulture, Gyeongsang National University, Jinju 52828, Korea \\ ${ }^{2}$ Institute of Agriculture \& Life Science, Gyeongsang National University, Jinju 52828, Korea \\ ${ }^{3}$ Department of Forest Environment Resources, Gyeongsang National University, Jinju 52828, Korea
}

\begin{abstract}
The purpose of this study was to assess the effects of plant mediated therapy on college student's academic exhaustion and stress. The program is composed of horticultural therapy activities and forest therapy activities that improve self-encouragement level and sense of self-esteem and relieve stress. The horticultural therapy program, which consisted of eight sessions of 10 sessions, was held in the lecture hall of $\mathrm{G}$ university, and the forest therapy program, consisting of the remaining sessions, were held in M mountain near $\mathrm{G}$ university. One lead researcher and one assistant researcher conducted program activities for an hour and a half each week from September 1 to November 10. The experimental group and the control group measured their self-encouragement, academic exhaustion, academic stress, and cumulative stress before and after the program. The pre- and post- test results of the plant mediated therapy program showed significant difference in the academic exhaustion $(p=.023)$, academic stress ( $p=.025)$, and cumulative stress ( $p=.027)$. However, there was no significant difference in self-encouragement test results. Based on these results, it was found that plant mediated activities positively affect college students' academic exhaustion and stress.
\end{abstract}

Keywords: forest therapy, horticultural therapy, self-encouragement

\section{Introduction}

Burnout is a condition of feeling discouraged and worn out while devoting oneself to something, described as an excessive demand on energy or strength resulting in loss of will, emotional exhaustion and depletion (Freudenberger, 1974). Earlier studies on burnout were mostly conducted on service workers engaged in emotional labor, but recently the scope has been expanded to studies on students whose principal task is to study (Schaufeli and Taris, 2005). Academic burnout, which is an extension of the concept of burnout, refers to the state of emotional exhaustion and cynicism about studies, and lack of academic confidence or achievement (Yang, 2004; Gan et al., 2007). Students experiencing academic burnout face difficulty and coldness in their studies, which may lead them to lose their academic motivations and discontinue their studies (Lee, 2009). In particular, university students are pressured by the so-called 'qualifications' required in employment, and they suffer academic stress from having to earn good grades and credits that are most closely

Received: April 5, 2018, Revised: May 18, 2018, Accepted: May 28, 2018

First author: Min Hui Lee, E-mail: 8rtminhui@gmail.com, ORCID: 0000-0002-5506-1906

*Comesponding author: Moo Ryong Huh, E-mail: mrhuh@gnu.ac.kr, ORCID: 0000-0001-8562-4901 
related (Lee, 2016). Excessive academic stress has negative effects on physical health such as headache, abdominal pain, fatigue and dizziness, as well as mental health such as depression, anxiety, suicide and insomnia (M.H. Kim, 2014; P.N.R. Kim, 2014; H.J. Park, 2015).

Accordingly, studies are conducted to reduce students' stress in the field of cognitive behavioral therapy, meditation, sports for all, and drama therapy, as well as to manage stress by having students encounter garden plants or participate in horticultural activities to manage stress (Hong, 2016). Horticultural activities bring composure and emotional stability in daily life, and make people feel relaxed and comfortable just by taking a look at plants as the natural green of the plants provides contrast with the gray of the city (Seo and Lee, 2004). With the expansion of the research fields on plantmediated therapy programs such as horticultural activities, interest in forest therapy as also increased recently.

Forest therapy includes natural and environmental resources as well as physical and psychological resources to cope with stress, thereby buffering the negative effects of stress, and encounter with nature performs a key role in maintaining and promoting psychological stability and physical health of humans (H.S. Park, 2015). Kaplan and Kaplan (1989) emphasized the importance of forests by referring to them as 'restorative environment' that restores fatigue from the urban environment without intentional effort.

As such, plant-mediated programs such as horticultural or forest activities perform a crucial role in maintaining and promoting physical and mental health of humans. Therefore, this study will conduct a plant-mediated therapy program combining horticultural and forest therapy for university students and determine the effects on their academic burnout and academic stress.

\section{Method}

\section{Subjects and method}

\section{Subjects}

The subjects of this study are 15 students in the experimental group and 15 students in the control group attending $\mathrm{G}$ University located in Jinju, Gyeongsangnam-do. These 30 students were selected among those who wanted voluntary participation from the announcement recruiting the subjects posted on the bulletin boards on campus and the university's

Table 1. Demographic characteristics of the study subjects

\begin{tabular}{lccc}
\hline \multicolumn{1}{c}{ Item } & Classification & Experimental group & Control group \\
\hline \multirow{3}{*}{ Gender } & Male & $5(35.7)$ & $7(50)$ \\
& Female & $9(64.3)$ & $7(50)$ \\
& Total & $14(100)$ & $14(100)$ \\
\hline \multirow{3}{*}{ Academic year } & $1-2$ year & $4(28.6)$ & $0(0)$ \\
& $3-4$ year & $10(71.4)$ & $14(100)$ \\
& Total & $14(100)$ & $14(100)$ \\
\multirow{2}{*}{ GPA on a 4.5 scale } & $2.5-3.5$ & $8(57.1)$ & $8(57.1)$ \\
& $3.5-4.5$ & $6(42.9)$ & $6(42.9)$ \\
& Total & $14(100)$ & $14(100)$ \\
\hline
\end{tabular}

Note. Values are numeric (percentage). 
website. Their prior consent is obtained after selection, and we conducted an experiment of plant-mediated therapy to reduce academic burnout and stress. One from the experimental group and one from the control group withdrew during the experiment, and thus total 28 subjects participated. Table 1 shows the demographic characteristics of the subjects. This study was approved by the institutional review board (IRB NO.GIRB-A17-Y-0031) of the university.

\section{Design and program implementation}

The program in this study consists of plant-mediated therapy activities for self-encouragement, confidence and stress relief, designed to measure how these affect self-encouragement, academic burnout, academic stress, and cumulative stress of university students. The pretest and posttest were conducted after dividing the subjects into the experimental group and control group (Table 2). The program was carried out in total 10 sessions in a lecture hall of G university and $\mathrm{M}$ mountain near G university from September 1 to November 10, 2017 for an hour and a half every week.

\section{Plant-mediated therapy program}

The program was carried out in total 10 sessions combining horticultural and forest therapy activities (Table 3). Each session is in the introduction, development and finishing stage. In the introduction, the principal therapist provides clues and questions about the contents of the program to be implemented that day. This process was to induce curiosity and interest of the subjects so that they can predict what kind of activity will begin. The development stage is when the subjects were to directly participate in the activities. They are given detailed explanations about the activities so that they can easily understand the contents and information, and are also shown the process of how the works are created. The program was assisted by asking adequate questions and showing interest so that the subjects that do not fit in with others or show a passive attitude can participate well in the program. In the finishing stage, the subjects introduced their works to one another and complimented on others, wrapping up the session by sharing their reviews of the activities.

The forest therapy activities among total 10 sessions of the program began in the fall, and thus they were included in sessions 3 and 5 that are at the beginning and the middle part of the program considering the weather getting cold, while all the other sessions were of horticultural therapy activities. The goal of sessions 3 and 5 consisting of forest therapy activities was to stimulate the five senses and sensitivity of the subjects, helping them feel the nature and perceive it as a living organism. They could also perceive their stress and learn to express it in the process of talking to a living tree, and relax their tense muscles and relieve stress through the body scan.

Sessions 1, 4, 8 and 10 were designed for the subjects to form rapport and feel love and gratitude through horticultural activities, and to discover their role by objectively reflecting on themselves. Kim (2002) stated that horticultural activities are the process of increasing pleasure, joy, self-esteem, confidence and desire for knowledge of humans. Sessions 2, 6, 7 and 9 included activities to promote concentration by engaging in making creative works. The program was designed in a biweekly pattern to balance the formation of rapport and promotion of concentration and self-esteem depending on the purpose of the therapy.

Table 2. Research design

\begin{tabular}{lccc}
\hline \multicolumn{1}{c}{ Group } & \multicolumn{2}{c}{ Process } \\
\hline Experimental group & $\mathrm{O}_{1}$ & $\mathrm{X}$ & $\mathrm{O}_{2}$ \\
Control group & $\mathrm{O}_{1}$ & & $\mathrm{O}_{2}$ \\
\hline
\end{tabular}

$\mathrm{O}_{1}=$ Pre-test; $\mathrm{O}_{2}=$ Post-test; $\mathrm{X}=$ Plant mediated therapy program. 
Table 3. Plant mediated therapy program

\begin{tabular}{|c|c|c|c|}
\hline & Topic by session & Materials & Goal \\
\hline 1 & $\begin{array}{l}\text { Orientation, pre-test and creating a } \\
\text { name tag with pressed flowers }\end{array}$ & $\begin{array}{l}\text { Rhodanthe manglesii } \\
\text { Hydrangea macrophylla } \\
\text { Argyranthemum frutescens }\end{array}$ & $\begin{array}{l}\text { Orientation, pre-test, rapport formation, enhancing } \\
\text { self-confidence about future, giving value to a } \\
\text { name }\end{array}$ \\
\hline 2 & Making a succulent plant pot & $\begin{array}{l}\text { Crassula perforata } \\
\text { Sedeveria cv. Fanfare } \\
\text { Echeveria peacockii }\end{array}$ & $\begin{array}{l}\text { Giving value to a plant that has vital power, } \\
\text { stimulating motivation and expectation about the } \\
\text { program }\end{array}$ \\
\hline 3 & $\begin{array}{l}\text { Feeling senses of body and talking with } \\
\text { trees }\end{array}$ & $\begin{array}{l}\text { Cryptomeria } \\
\text { Chamaecyparis obtusa } \\
\text { Pinus densiflora }\end{array}$ & $\begin{array}{l}\text { Stimulating five senses, } \\
\text { recognizing nature as a living organism, } \\
\text { recognizing stress factor and releasing stress }\end{array}$ \\
\hline 4 & $\begin{array}{l}\text { Making a dream note with pressed } \\
\text { flowers }\end{array}$ & $\begin{array}{l}\text { Rhodanthe manglesii } \\
\text { Hydrangea macrophylla } \\
\text { Argyranthemum frutescens }\end{array}$ & Self-reflection on dreams \\
\hline 5 & Meditating in forest & $\begin{array}{l}\text { Cryptomeria } \\
\text { Chamaecyparis obtusa } \\
\text { Pinus densiflora }\end{array}$ & $\begin{array}{l}\text { Stimulating five senses, recognizing nature as a } \\
\text { living organism }\end{array}$ \\
\hline 6 & Making a topiary doll & Hedera helix & $\begin{array}{l}\text { Improving self-esteem, giving confidence and } \\
\text { courage through creations, increasing immersion }\end{array}$ \\
\hline 7 & Creating a flower basket & $\begin{array}{l}\text { Chamaecyparis obtusa, } \\
\text { Chrysanthemum morifolium } \\
\text { Dianthus caryophyllus }\end{array}$ & $\begin{array}{l}\text { Improving self-esteem, giving confidence and } \\
\text { courage through creations, increasing immersion }\end{array}$ \\
\hline 8 & Making gift cards with pressed flowers & $\begin{array}{l}\text { Rhodanthe manglesii } \\
\text { Hydrangea macrophylla } \\
\text { Argyranthemum frutescens }\end{array}$ & Having a heart of gratitude, love, and consideration \\
\hline 9 & Making an herb garden & $\begin{array}{l}\text { Plectranthus tomentosa } \\
\text { Mentha piperita }\end{array}$ & $\begin{array}{l}\text { Giving a meaning of life, promoting responsibility } \\
\text { as an administrator of herb garden }\end{array}$ \\
\hline 10 & Herb tea, aroma massage and final-test & $\begin{array}{l}\text { Lavandula } \\
\text { Matricaria recutita } \\
\text { Aspalathus linearis }\end{array}$ & $\begin{array}{l}\text { Having a heart of gratitude, love, and belonging, } \\
\text { post-test, final session }\end{array}$ \\
\hline
\end{tabular}

\section{Measurement tools}

(1) Demographic variables

The demographic variables in this study consist of 3 items: gender, year and grade.

\section{(2) Self-encouragement}

Based on the previous study (Lingg and Wilborn, 1992) that encouragement and disappointment in the selfencouragement-disappointment scale developed by Noh and Jeong (2007) must be distinguished in two different concepts instead of putting them along the same line, we used only 30 items of self-encouragement excluding 30 items of disappointment. This scale consists of 10 items each for 3 sub-factors of cognitive, behavioral and emotional selfencouragement. The items are rated on a 5-point Likert scale, with higher scores indicating higher self-encouragement. The Cronbach $\alpha$ coefficient of the measurement tool is .96 .

\section{(3) Academic burnout (Maslach Burnout Inventory-Student Survey: MBI-SS)}

Academic burnout of students was measured with the MBI-SS developed by Schaufeli et al. (2002) for university students and validated by Shin et al. (2011) for Korean students. The scale consists of total 15 items rated on a 5-point 
Likert scale: 5 in exhaustion, 4 in cynicism, and 6 in inadequacy. Inadequacy was obtained by reverse scoring after measuring adequacy, with higher scores indicating stronger tendency of academic burnout. The Cronbach $\alpha$ coefficient of the measurement tool is .88.

\section{(4) Academic stress}

Academic stress was measured by the questionnaire modified and improved by Kang (2014) to meet the purpose and subjects of research based on the study results of Oh and Cheon (1994). Considering that the contents are negative, a factor analysis was conducted after reverse coding of all items of academic stress. There are total 14 items of academic stress: 5 in expectation, 5 in internalization, and 4 in expression. They were rated on a 5-point Likert scale, and the Cronbach $\alpha$ coefficient of the measurement tool is .85 .

(5) uBioClipv measurement of heart rate variability (HRV)

Cumulative stress was measured using uBioClipv 70 developed by Biosense Creative, a Korea Institute of Science and Technology venture business. The subjects were measured before the first session of the plant-mediated therapy program on September 1, 2017 and after session 10 on November 10. They were to place their forefingers in the device sitting in a chair and measured for 2 minutes and 30 seconds. Cumulative stress can be determined by analyzing the cardiomotility and HRV, with higher scores indicating more cumulative stress.

\section{Data analysis}

The following statistical analysis is conducted to determine the effects of the plant-mediated therapy program on self-encouragement, academic burnout, academic stress, and cumulative stress of university students. The Mann-Whitney test was used to verify the homogeneity of the two groups before the program, and the Wilcoxon Signed-Rank test was used for pre-test and post-test. IBM SPSS 24 was used for all statistical analysis.

\section{Results and discussions}

\section{Homogeneity test between the study groups}

The Mann-Whitney test was conducted to determine the homogeneity of the experimental group and control group

Table 4. Verification of homogeneity of an experimental and a control group

\begin{tabular}{|c|c|c|c|c|c|}
\hline Variable & Group & M & SD & $\mathrm{z}$ & $p$ \\
\hline \multirow{2}{*}{ Self-encouragement } & Exp. ${ }^{\mathrm{z}}$ & 107.78 & 25.371 & \multirow{2}{*}{-.046} & \multirow{2}{*}{$.982^{\mathrm{NS}}$} \\
\hline & Cont. $^{\mathrm{y}}$ & 110.14 & 23.290 & & \\
\hline \multirow{2}{*}{ Academic burnout } & Exp. & 45.28 & 6.402 & \multirow{2}{*}{-1.105} & \multirow{2}{*}{$.285^{\mathrm{NS}}$} \\
\hline & Cont. & 42.57 & 6.357 & & \\
\hline \multirow{2}{*}{ Academic stress } & Exp. & 46.50 & 9.296 & \multirow{2}{*}{-1.863} & \multirow{2}{*}{$.062^{\mathrm{NS}}$} \\
\hline & Cont. & 53.35 & 8.731 & & \\
\hline \multirow{2}{*}{ Cumulative stress } & Exp. & 37.21 & 6.795 & \multirow{2}{*}{-.760} & \multirow{2}{*}{$.454^{\mathrm{NS}}$} \\
\hline & Cont. & 38.85 & 6.514 & & \\
\hline
\end{tabular}

${ }^{\mathrm{z}}$ Exp. $=$ Experimental group; ${ }^{\mathrm{y}}$ Cont. $=$ Control group.

${ }^{\mathrm{NS}}$ non-significant by Mann-Whitney test. 
Table 5. Comparing self-encouragement between experimental group and control group before and after plant mediated therapy activity

\begin{tabular}{|c|c|c|c|c|c|c|}
\hline \multirow{2}{*}{ Group } & \multicolumn{2}{|c|}{ Pre } & \multicolumn{2}{|c|}{ Post } & \multirow{2}{*}{$\mathrm{z}$} & \multirow{2}{*}{$p$} \\
\hline & M & SD & M & SD & & \\
\hline Experimental $(\mathrm{n}=14)$ & 103.14 & 20.765 & 107.78 & 25.371 & -1.399 & $.162^{\mathrm{NS}}$ \\
\hline Control $(n=14)$ & 106.14 & 20.045 & 110.14 & 23.290 & -.663 & $.507^{\mathrm{NS}}$ \\
\hline
\end{tabular}

${ }^{\mathrm{NS}}$ non-significant by Wilcoxon signed-rank test.

regarding self-encouragement, academic burnout, academic stress, and cumulative stress. The result showed that the items were not statistically significant, and thus the homogeneity of the two groups was verified (Table 4).

\section{Effects of plant-mediated therapy activities on self-encouragement}

Table 5 shows the result of the self-encouragement test of the experimental-control group before and after the program to analyze the effects of the plant-mediated therapy program. Self-encouragement in the experimental group $(p=.162) \mathrm{did}$ not show a statistically significant difference, and neither in the pretest and posttest result of the control group $(p=.507)$. According to Bahlmaan and Dinter (2001), the result of a program promoting self-encouragement showed that self-worth, psychological well-being and positive emotions of adult participants increased, whereas anxiety, depression and compulsion decreased. This study showed different results from previous studies due to the psychological response of the subjects.

The subjects promised themselves to tend the herb garden or succulent pots they made in order to encourage themselves during the program. They also read the positive messages written on their pots once a day. Those who kept the promise of taking good care of the plants and reading positive messages perceived themselves to have done a good job taking care of their plants and thus their self-encouragement increased as they reflected on the positive messages. However, those who did not take good care of their plants showed guilt and despair for failing. Due to the awareness that they failed to keep their own promise rather created negative emotions more than the anticipated positive response. This may have brought conflicts among the factors, thereby affecting the result of self-encouragement. According to Ju (2013), parents that fail to properly perform their roles in childcare feel more guilt and stress as they are pressured by not taking good care of their children.

\section{Effects of plant-mediated therapy activities on academic burnout}

Table 6 shows the result of the academic burnout test of the experimental-control group before and after the plant-mediated therapy program. The experimental group showed a significant difference in the result of academic burnout ( $p=.023)$, whereas the control group did not $(p=.694)$. This may be due to the fact that the participants could be

Table 6. Comparing academic burnout between experimental group and control group before and after plant mediated therapy activity

\begin{tabular}{|c|c|c|c|c|c|c|}
\hline \multirow{2}{*}{ Group } & \multicolumn{2}{|c|}{ Pre } & \multicolumn{2}{|c|}{ Post } & \multirow{2}{*}{$\mathrm{z}$} & \multirow{2}{*}{$p$} \\
\hline & M & SD & $\mathrm{M}$ & SD & & \\
\hline Experimental $(\mathrm{n}=14)$ & 45.28 & 6.402 & 40.92 & 4.445 & -2.277 & $.023^{*}$ \\
\hline Control $(\mathrm{n}=14)$ & 42.57 & 6.357 & 43.07 & 7.579 & -.394 & $.694^{\mathrm{NS}}$ \\
\hline
\end{tabular}

${ }^{*} p<.05,{ }^{\mathrm{NS}}$ non-significant by Wilcoxon signed-rank test. 
separated from their helplessness, sense of loss or defeat about their studies in the process of participating in the plant-mediated therapy activities. Moreover, their engagement increased in the process of making creative works with their special significance, and their self-esteem, confidence and self-respect increased as they can do something on their own during the process, thereby showing positive effects. Choi (2003) stated that horticultural therapy can increase social interaction, physical activities, psychological stimulation, natural expression, self-esteem and voluntary activities.

The observation results also support these findings. The participants rarely communicated with one another at first because they had met for the first time in the program. But as they participated in one session after another, rapport was formed between participants and therapists or among participants, resulting in more relaxed and natural activities. Communication among participants became active from the middle of the program, and they could change their attitude toward problematic life by sharing the meaning of their works and resolutions about their studies. The participants' faces looked brighter as they went through the sessions, showing anticipation for the next session and enthusiasm in activity participation.

\section{Effects of plant-mediated therapy activities on academic stress}

Table 7 shows the result of the academic stress test of the experimental-control group before and after the plantmediated therapy program. The experimental group showed a significant difference in the result of academic stress ( $p=.025)$, whereas the control group did not $(p=.361)$. This is because the participants perceived the cause of their stress through the plant-mediated therapy program and learned how to efficiently manage their stress factors. In particular, group members had complained about the travel range in the forest during the forest therapy activity, but by the finishing stage of Session 5, they confessed that just being in a forest relieves their stress and makes them feel refreshed. According to Kaplan and Kaplan (1989), people today suffer from mental and physical pain because they lack contact with nature due to the complicated city life, and forests provide psychological stability and restoration like a resting place. Jeon (2012) reported that phytoncide, the substance discharged by trees as a resistance to pathogen, injurious insects and mold, lowers the blood concentration of cortisol created when stressed, thereby reducing stress and increasing immunity.

\section{Effects of plant-mediated therapy activities on cumulative stress}

Figure 1 shows the result of measuring cumulative stress with uBioclipv before and after the plant-mediated therapy program. The mean score of cumulative stress decreased from the pretest mean $(\mathrm{M}=37.21 \pm 6.795)$ to post-test mean $(\mathrm{M}=31.50 \pm 5.680)$ in the experimental group, showing a statistically significant difference ( $p=.027)$. On the other hand, the mean score in the control group increased from the pretest mean $(\mathrm{M}=38.85 \pm 6.514)$ to post-test mean $(\mathrm{M}=40.00 \pm$ $6.348)$, without showing a significant difference $(p=.248)$. The result showed that 10 sessions of the program had effects on reducing cumulative stress of university students.

Table 7. Comparing academic stress between experimental group and control group before and after plant mediated therapy activity

\begin{tabular}{|c|c|c|c|c|c|c|}
\hline \multirow{2}{*}{ Group } & \multicolumn{2}{|c|}{ Pre } & \multicolumn{2}{|c|}{ Post } & \multirow{2}{*}{$\mathrm{z}$} & \multirow{2}{*}{$p$} \\
\hline & $\mathrm{M}$ & SD & M & SD & & \\
\hline Experimental $(\mathrm{n}=14)$ & 46.50 & 9.296 & 34.35 & 9.644 & -2.238 & $.025^{*}$ \\
\hline Control $(n=14)$ & 53.35 & 8.731 & 50.14 & 13.254 & -.913 & $.361^{\mathrm{NS}}$ \\
\hline
\end{tabular}

${ }^{*} p<.05,{ }^{\mathrm{NS}}$ non-significant by Wilcoxon signed-rank test. 


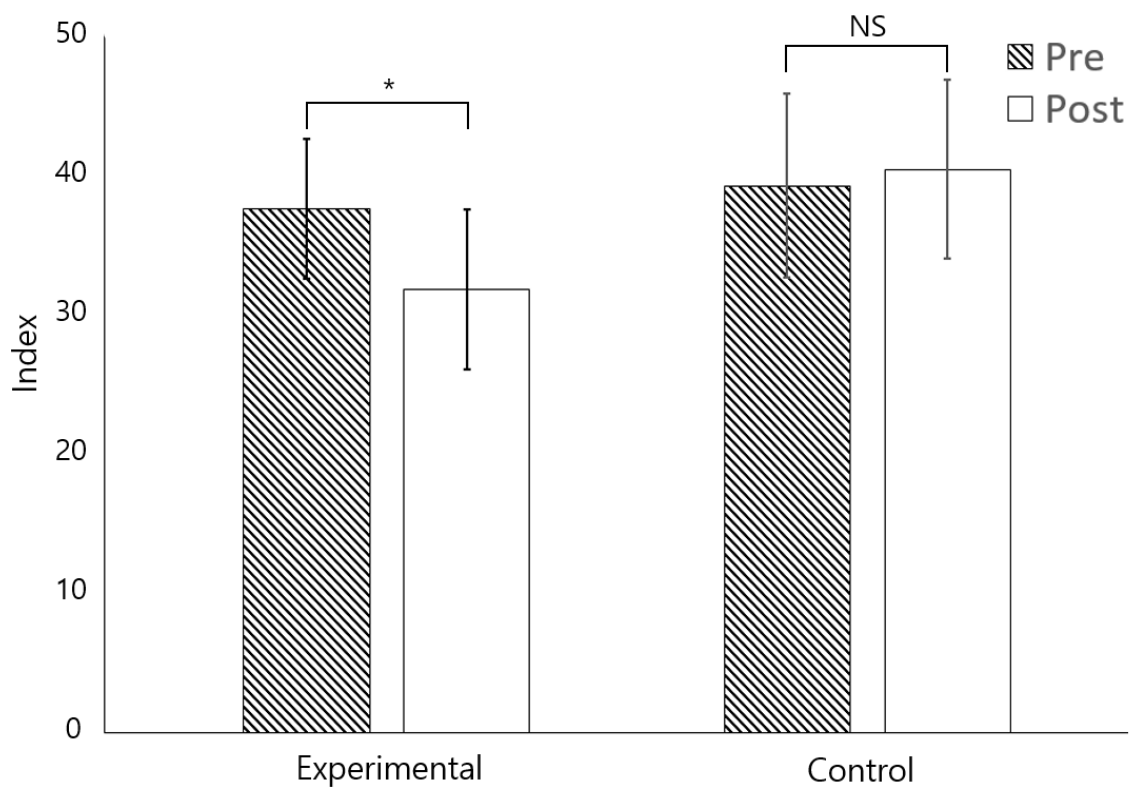

Figure 1. Comparing cumulative stress between experimental group and control group before and after plant mediated therapy activity. Pre=pre plant mediated therapy; Post=post plant mediated therapy. Data represent the mean \pm SD (Significant as compared to Pre. ${ }^{*} p<.05,{ }^{\text {NS }}$ non-significant by Wilcoxon signed-rank test).

\section{Conclusion}

This study was conducted to determine the positive effects of a plant-mediated therapy program combining horticultural and forest therapy on academic burnout and stress of university students. As a result of carrying out 10 sessions of the plant-mediated therapy program with 28 university students, there was no statistically significant difference in the self-encouragement scale for both the control group and experimental group $(p=.162)$. Academic burnout did not show a significant difference in the control group, but showed a significant difference in the experimental group $(p=.023)$. Academic stress did not show a significant difference in the control group, but showed a statistically significant difference in the experimental group. The additional analysis of cumulative stress also showed a significance difference before and after the program in the experimental group like academic stress.

The result of this study showed that the plant-mediated therapy activity combining horticultural and forest therapy was effective in reducing academic burnout, academic stress, and cumulative stress of university students. There are limitations in generalizing the results because the sample size was small, but the significance is in applying a program that combined horticultural and forest therapy, which has not been generally discussed in the field of research on horticultural and forest therapy. It is necessary to analyze the stress differences before and after the program for university students with high scores in academic burnout instead of general university students for more detailed analysis.

\section{References}

Bahlmann, R. and L.D. Dinter. 2001. Encouraging self-encouragement: An effect study of the encouraging-training schoenaker-concept. J. Individ. Psychol. 57(3):273-288.

Choi, Y.A. 2003. Horticultural Therapy. Seoul, Korea: Hakjisa Press.

Freudenberger, H.J. 1974. Staff burn-out. J. Soc. Issues 30(1):159-165. DOI:10.1111/j.1540-4560.1974.tb00706.x 
Gan, Y., J. Shang, and Y. Zhang. 2007. Coping flexibility and locus of control as predictors of burnout among Chinese college students. Soc. Behav. Pers. 35(8):1087-1098. DOI:10.2224/sbp.2007.35.8.1087

Hong, J.S. 2016. Horticultural cognition and stress response of white-collar workers. Master's thesis, Dankook University, Yongin, Korea.

Jeon, H.S. 2012. I go to cypress forest to meet green doctor. Forest 12:32-35. Retrieved from http://www.sanrimji.com/ sites/websolution/files/old/pdf/2012/12/201212032-035(1).pdf

Ju, Y.J. 2013. Exploration of variable related to the parenting guilt of mothers with infants and young children. Master's thesis, Gachon University, Seongnam, Korea.

Kang, C.W. 2014. The relationship between study stress, academic attitude, school adjustment by Taekwondo major college students. Doctoral dissertation, Kyunghee University, Seoul, Korea.

Kaplan, R. and S. Kaplan. 1989. The Experience of Nature: A Psychological Perspective. New York, NY: Cambridge University Press.

Kim, M.H. 2014. The effect of adolescents'academic stress on mental health: the moderating role of academic resilience. Master's thesis, Kyungnam University, Changwon, Korea.

Kim, M.S. 2002. Study on effects of horticultural therapy on self-esteem and depression of family violence women victims at shelter. Master's thesis, Dongguk University, Seoul, Korea.

Kim, P.N.R. 2014. The relations between academic stress and smart-phone addiction: dual mediating effects of anxiety and experiential avoidance. Master's thesis, Catholic University, Seoul, Korea.

Lee, S.A. 2016. A study on relationship between adaptive, maladaptive perfectionism and academic burnout of university students: the mediating effects of internal locus of control and self-encouragement. Master's thesis. Ewha University, Seoul, Korea.

Lee, Y.B. 2009. Development and validation of academic burnout scale for adolescents. Master's thesis, Korea University, Seoul, Korea.

Lingg, M. and B. Wilborn. 1992. Adolescent discouragement: Development of an assessment instrument. Individ. Psychol: J. Adlerian Theory Res. Pract. 48(1):65-75.

Noh, A.Y. and M. Jeong. 2007. Development and validation and the self encouragement-discouragement inventory. Korean J. Couns. Psychother. 19(3):675-692.

Oh, M.H. and S.M. Cheon. 1994. Analysis of academic stressors and symptoms of juveniles and effects of meditation training on academic stress reduction. J. Hum. Underst. Couns. 15:63-96. Retrieved from http://sgjhuc.sogang.ac.kr/

Park, H.J. 2015. Moderating role of social support in the relations between academic stress and school-aged children's somatic symptom. Master's thesis, Ewha University, Seoul, Korea.

Park, H.S. 2015. The Effect of Jangseong forest healing program on recovering psychological and physical stress. Master's thesis, Chungbuk University, Cheongju, Korea.

Schaufeli, W.B., I.M. Martinez, A.M. Pinto, M. Salanova, and A.B. Bakker. 2002. Burnout and engagement in university students: A cross-national study. J. Cross Cult. Psychol. 33(5):464-481.

Schaufeli, W.B. and T.W. Taris. 2005. The conceptualization and measurement of burnout: Common ground and worlds apart. Work \& Stress 19(3):256-262. DOI:10.1080/02678370500385913

Seo, J.K. and S.M. Lee. 2004. Application and Practice of Horticultural Therapy Process. Seoul, Korea: Dankook University Press.

Shin, H., A. Puig, J. Lee, J.H. Lee, and S.M. Lee. 2011. Cultural validation of the Maslach burnout inventory for Korean students. Asia Pacific Educ. Rev. 12(4):633-639. DOI:10.1007/s12564-011-9164-y

Yang, H.J. 2004. Factors affecting student burnout and academic achievement in multiple enrollment programs in Taiwan's technical-vocational colleges. Int. J. Educ. Dev. 24(3):283-301. DOI:10.1016/j.jjedudev.2003.12.001 